\title{
Teaching English for Sustainability
}

\section{Rachel Bowden}

\begin{abstract}
:
In this article I begin by exploring ideas of sustainability and the emergence and prevalence of this term into international discourse. I then outline the connection between learning and sustainability and the emerging field of Education for Sustainability (EfS). I go on to draw parallels between EfS and English Language Teaching (ELT) suggesting that what, how, who and where we teach, gives us an exciting role to play in this emerging paradigm of education and wider societal changes- why we teach. I finish by making suggestions for strengthening this connection.
\end{abstract}

\section{Key words: sustainability, English for sustainability, teaching English}

\section{Introduction}

The sustainability debate has emerged from an awareness of just how unsustainable many of our widely accepted practices, and the assumptions that inform them, are.

These assumptions include an almost religious belief in the power of the market and the omnipotence of science and technology to liberate humanity from the constraints of nature and society (Berthaud, 1997). They have led to the commodification of food, labour and the environment. As a result, whole populations have become disconnected from themselves, each other and their surroundings with disastrous consequences for the global system (Robert, 1992).

Consequently, we are now entering a new geological epoch, the 'anthropocene', in which "humanity is having planet wide impacts on the Earth's workings" (Lewis, 2009).

Evidence of this un-sustainability is seen at local and global levels; in communities and societies, economies and environments. Underpinning the concept of sustainability is an ecological, rather than a reductionist, way of seeing the world. An ecological world view sees these issues as connected, part of a global system "whose stability rests on the equilibrium of its components" (Sachs, 1997 p. 27). The component systems are “(...) themselves systems, and are not sustainable separate from the larger systems in which they exist." (CEL, 2009).

This reciprocity and extreme interconnectedness implies complex, non linear, relationships of cause and effect. Therefore a negative impact on one area, for example the environment has a knock on effect in communities and economies, which is an inherently circular and complex 'feedback loop'.

Sustainability within this world view is therefore the process whereby these interlinked systems maintain themselves and each other. It demands us to consider connections, and the whole over individuals and elements, as in a system the individual or component parts are deeply connected to the whole, which in turn contains "properties (...) which are possessed by none of the parts" (CEL, 2009).

Achieving greater sustainability means fundamentally addressing the way we see ourselves in connection to others, and the world around us. It does not just mean changing behavior or 'green washing' but examining and reformulating some of our most closely held assumptions. 


\section{An Emerging Concept}

Although the need for greater sustainability is irrefutable, and indeed features in main stream political discourse (Obama, 2009), there remain underlying ambiguities in its conception and expression. One false assumption is that the notion of sustainability is fully understood and clearly defined, partly due to the mechanistic language which we use to describe it (Sachs, 1997 pp. 30-32). Rather than the world view which I believe it implies, sustainability is often expressed as a problem of limited resources which can only be remedied through ever greater technology and centralisation of power. For example, the slogan Monsanto used to advertise GM crops in the UK "worrying about future generations won't feed them; food biotechnology will" (1998 cited in The Guardian weekly 21/08/2009).

In the same way 'sustainable' is frequently used as an adjective to qualify, and implicitly justify, 'development'. This assumes that both terms are clear and compatible. We are left with a paradox that awareness of growing global imbalance, arguably as a direct result of the mindless pursuit of economic growth or 'development', is being used as the justification for greater development. In this way the term sustainability and its accompanying ecological world view has been appropriated by the development armoury, rather than undermining it (Sachs, 1997).

Sachs (1997) suggests that as systems theory uses a mechanistic model for interpreting ecology it is essentially reductive, and used to justify even great levels of intervention. However, in my view, the ambivalence of the term sustainability and the metaphors we use to understand it is inevitable. A discourse which is currently dominated with mechanistic metaphors will only conceive organicism in such terms. Only through a process of critical exploration of the ideas connected to sustainability, and the location of ourselves and others within the emergent paradigm, we can begin to formulate these new ways of seeing which will in turn transform our language. In this process "how we see the world shapes the world and this in turn shape us" (Sterling, 2001, p. $50)$.

\section{Education and Sustainability}

Learning is inherent in moving towards greater sustainability as "sustainable systems are those which are (...) able to learn in order to maintain and adapt themselves" (Sterling, 2001 p. 54). The emerging field of Education for Sustainability (EfS) aims for educational experiences to facilitate this change towards more sustainable societies. The assumption is of continuous learning for all, children and adults, teachers and learners, individuals, communities and organizations alike.

Within formal education, EFS is a direct challenge to the dominant and accepted model which prepares children to follow behavioural norms of society and contribute towards economic growth (Bartlett, 2004). Instead the onus, at once more radical and creative, is on creating "citizens capable of designing and maintaining sustainable societies" (CEL, 2009).

Rather than imparting objective knowledge to passive students, this implies developing a range of critical and reflective competencies such as those described the Centre for Eco-Literacy (2009):

- The ability to think systemically

- Theability to think critically, to solveproblems creatively, and to apply environmental ethics to new situations

- The ability to assess the impact of human technologies and actions and to envision the long-term consequences of decisions

- Empathy and the ability to see from and appreciate multiple perspectives

- A commitment to equity, justice, inclusivity, and respect for all people

- Skills in building, governing, and sustaining communities

- Practical skills to create and use tools, objects, and procedures required by sustainable communities

- The ability to assess and make adjustments to uses of energy and resources

- The capacity to convert convictions into practical and effective action

There is also an emphasis on collaborative working, intercultural awareness and interpersonal skills accepting that we as individuals are connected to communities, locally, nationally and globally. 


\section{Connections between EfS and ELT}

\section{What we teach}

With over a billion speakers all over the world, English is no longer simply a language of the British. Englishes are used in a multitude of contexts to express a diversity of views and narratives in global discourse, and are the medium for emerging ideas (Crystal, 2003). As a medium for creativity, international dialogue and debate English, itself a site of ambiguity, can be used as a medium for identifying assumptions and reformulating knowledge (Rushdie, 1991).

Rather than replacing local languages, English exists within multilingual societies as a tool for accessing ideas and opportunities, for participating in specific contexts and with specific communities (Graddol, 2010). These include accessing research, training and education, conducting business, accessing technology (another great enabler and connector) social or special interest networking groups.

The acceptance of the organic nature of English, including multiple and ever multiplying varieties, is fundamentally a celebration of diversity, adaptation and life. At the same time is a continual negotiation of a global English, demanding that we listen to and learn from each other in order to be able to communicate across cultural and spatial boundaries.

The spread and increasing prevalence of English has been closely connected with the spread of a western worldview, and inherent assumptions, which I suggest it can be used to challenge. I believe that through teaching English we can and should locate, trace and challenge the assumptions embedded within it. It is crucial that English language teachers are prepared to reflect on the implicit and explicit assumptions in the language they use and teach, and facilitate this critical awareness in their learners. Teachers must realise that "the acquisition and development of literacy is not, and cannot be, a neutral process" (Bartlett, 2004 p. 81).

The possibilities for using English within a transformative learning context are continually expanding. One such project is the Skills Through English for Public Servants project in Sri Lanka.
On this course skills, such as critical thinking, concepts such as free market trade and inequality, and language competencies such as report writing are integrated. Case studies set in local contexts are used to explore concepts such as 'good governance' and 'conflict', through which assumptions are identified and associations re-formed (Kennet, 2009).

\section{How we teach}

EfS is "a way of thinking as much as what we are thinking about" (Wheeler and Bijur, 2000 cited in Bhandari and Obe, 2003 p. 23). From this perspective, we can see that methodology (how) is fundamentally connected to content (what).

Within ELT the English language was traditionally what was taught. However, over the past 50 years, views on language teaching and learning have shifted. Previously accepted teaching methods saw language as objective, for example grammar translation where learners memorised and translated written texts (Richards and Rodgers, 1986).

In contrast, current approaches such as the communicative approach, see language as inherently subjective in both production and interpretation, functional (both interactional and transactional (Brown and Yule, 1987), and part of a system of interacting 'messages' operating within a specific context (Richards and Rodgers, 1986). In my view this evolution of understanding mirrors the move from a mechanistic to an ecological educational paradigm (Sterling, 2001pp. 58-59).

Furthermore shifts in methodology have echoed shifts in thinking about language itself. For example in the now widely practised Lexical Approach (Lewis, 1993) vocabulary is taught in contextualised chunks, rather than isolated words, and the emphasis is on learners noticing patterns of use in context rather than learning fixed rules connected to single words. From this view demarcations such as grammar and vocabulary are increasingly obsolete as language is seen as systemic, and words gain meaning through relationships with other words and the surrounding context.

Current ELT practise, called the eclectic or sometimes simply the communicative approach is 
in fact a mixture of many different methodologies, or 'tools'. Within a set of emergent beliefs about the nature of teaching, learning and language, teachers select from a range of methodologies to suit each learning context (Hedge, 2000). An example of these beliefs is:

1) Learning is facilitated if the learner discovers or creates rather than remembers or repeats (...)

3) Learning is facilitated by problem solving involving the material to be learned.

(Richards and Rodgers, 1986)

ELT has come to embrace a humanistic approach, seeing the learner central to their own learning, and considering issues such as the motivation, principles and commitment of the learner to be crucial (Stevick, 1980). Moreover Multiple Intelligence theorists have helped us to recognise the rich diversity within our classes, challenging the idea of a single intelligence, and encouraging us to create diverse learning experiences to reflect this.

Methodologies such as community based learning and task based learning recognise the value of collaboration and group work (Overfield, 1997). This can be seen in the layout of ELT classrooms where tables are arranged to promote various dynamics of collaborative working for example 'islands', 'horse shoe' or 'circles' (Overfield, 1997; Hedge, 2000).

Clearly not all English teachers have access or support to teach using these approaches. Especially in formal education, teachers face challenges such as big classes, the culture of the school and fixed perceptions of the roles of teachers and learners, exam oriented courses and compulsory course books. However, I think that identifying and discussing the rationale behind these methodologies is a crucial step in enabling teachers to act more as experts within their contexts. We know these methods work, and we can directly connect them with skills and competencies which are in demand in the work place of today, and will help to build a better tomorrow.

In contrast to the restrictions faced by teachers working in formal education systems, the transformative possibilities of teaching skills through English have been explored in many informal education projects and initiatives. In her paper, 'English as a tool for conflict transformation', Kennet (2009) reflects "how the delivery of the course can mirror the content to optimise learning outcomes and behavioural change" (Kennet, 2009).

The methodology used in STEPS is task based and collaborative, based on problem solving using case studies from local contexts. Learners are supported to take control of their own learning through support organising their work and assessing their own progress. Language is seen as a means of communication, related to specific (and in this case, local) contexts (Kennet, 2009). As a trainer on this course I was able to see the process of transformation, in which I was also involved, in action.

\section{Where/who we teach}

The scale of the EfS project demands personal, local, national and global participation in debates about sustainability. Rather than a one size fits all answer this vision of EfS calls for local negotiation of meaning. This implies building the capacity of individuals, learners and teachers, to create appropriate learning experiences. At the same time, EfS demands leaning from all sectors of society, civil, state and business, indeed cross sectoral learning gives us the biggest chance of societal change.

The use of English by speakers of other languages is widespread, with learners extending far beyond the realm of formal education:

The evidence suggests that English is now the dominant voice in international politics, banking, the press, the news agencies, advertising, broadcasting, the recording industry, motion pictures, travel, science and technology, knowledge management, and communications. No other language has achieved such a widespread profile - or is likely to, in the foreseeable future. (Crystal, 2003)

Moreover, English language teaching often surpasses the boundaries of language instruction. At the British Council worldwide a significant 
proportion of all courses are run off site in state, NGO or corporate sectors. Courses such as communication skills, report writing, team building, leadership, creativity, and critical thinking reflect the now widely held understanding that language and communication skills are interconnected. As beliefs and values are implicit in any process of communication I feel the classroom can be an ideal site for their exploration.

Within the ELT classroom cultural norms that restrict people communicating together are often removed, which can have a ripple effect into the wider community. Kennet (2009) suggests that approaches used in the classroom, functioning as a microcosm of community, can directly transfer to use in the workplace, and wider society.

Moreover English and the associated socio economic advantages that go with it, provide a strong incentive for learning. For example in India where parents have demanded that English be taught from Primary School, against the advice of intellectuals and advisors (many of whom send their children to English medium schools), (Graddol 2010).

\section{Strengthening the Connection}

Although I believe that there are many connections between EfS and ELT, the fact that this is not discussed limits the association. Despite many teacher training courses emphasising reflective practise, connections between teaching methodologies and their wider ideological context are seldom explored below masters level.

\section{Why we teach}

I think that an orientation in EfS, related to both the methodology and content of ELT, would enable teachers to actively select 'tools' coherent with this vision as well as engaging students in this process. Moreover considering EfS through English teaching would offer rich opportunities for cross sectoral working, for example with UN or conservation agencies. It would also prove motivating for teachers and students. Why shouldn't we discuss real world issues, develop real skills and effect real change at school? For both teachers and students a personal orientation on the sustainability debate would encourage them to engage with discussions on all levels, enabling them to be agents for change.

In my view there are many ways in which the sustainability focus of ELT could be strengthened. Here are a few suggestions:-

- Encouraging teachers to explore wider debates about sustainability and society and to make the connection education and their classrooms.

- Giving teachers the opportunity to select, develop and adapt activities and content relevant to their contexts and their students.

- Reformulating curricula to reflect an ecological world view. Instead of reductive isolated 'fact' based subjects, we should aim toward integrating subjects and teaching skills and competencies i.e. learning to learn, critical thinking, creativity, managing change and conflict. For language teachers this means an emphasis on collaborative task based learning, on language production and use, the study of and response to authentic language in context.

- Relating teaching material to both personal and local concerns as well as connecting it to wider debates. For example by using learners' own experiences and opinions as the basis for discussion rather than set texts, or incorporating authentic texts and subjecting them to critical analysis,

- Greater emphasis on EfS competencies such as critical thinking from a systemic view point, the construction rather than instruction of meaning and collaborative working (Sterling, 2001).

- Greater connection with the local community and local issues, for example inviting local people to present ideas or going out and interacting for example conducting surveys, recording narratives.

- $\quad$ Ongoing dialogue with the wider learning institution, aiming for a clear policy statement making transparent views about learning and societal change. This would ensure that curricula and organisational practises are coherent with this view and help to transform learning organisations at all levels. 


\section{Conclusion}

In this article, I explored the term sustainability and associated ecological worldview, the connections with education and the parallels between Education for Sustainability and English Language Teaching. I also made suggestions for furthering this association, through building the capacity of teachers.

To strengthen the impact of ELT on sustainability, it is important to open the vision, image and design of sustainable education to discussion. I believe that empowering ELT teachers and learners to engage with the wider society in exploring, developing and manifesting sustainability values will enable them to act as agents for change.

Rachel Bowden grew up in the UK where she studied theatre
and literature. She's lived and worked in Nicaragua, France,
Malaysia, Sri Lanka, Nepal, India and Bhutan as a teacher
and teacher trainer. She is currently working on an early
primary teacher support programme in Sabah, East Malaysia.
Her special interest areas include education for sustainability
and teacher development, as well as theatre and creative
education.

\section{References}

Bartlett, S., Burton, D. \& Peim, N. (2004). Introduction to education studies. London: Paul Chapman Publishing.

Bhandari, B. \& Abe, O. (eds.) (2003). Education for sustainable development in Nepal. Views and visions. IGES Japan [Online] http:// enviroscope.iges.or.jp/modules/envirolib/ view.php?docid=1515 [09/09/2009]

Brown, G. \& Yule, G. (1983). Teaching the spoken language. Cambridge: Cambridge University Press.

Centre for Eco-Literacy [online] http://www. ecoliteracy.org [07/09/2009]

Crystal, D (2003). English in the new world [Online] http://www.matefl.org/_mgxroot/page_10658. html [09/09/2009]
Graddoll, D. (2010). English next. India: British Council.

Hedge, T. (2000). Teaching and learning in the language classroom. Oxford: Oxford University Press.

Kennet, P. (2009). English as a tool for vonflict transformation. A paper presented at $8^{\text {th }}$ International Conference on Language and Development. Dhaka, Bangladesh.

Lewis, M. (1993). The lexical approach. London: language Teaching Publications (LTP).

Lewis, S. (2009). Humans, a crushing force of nature. The Guardian Weekly, 31/07/2009: p19

Monsanto (1998). cited in Bennet, C (2009) What's the Power of Monsanto? In The Guardian Weekly 21/08/2009 p. 21.

Obama, B. (2009). Economy. [Online] http://www. barackobama.com/issues/

Overfield, D. (1997). From the margins to the mainstream: Foreign language education and community-based learning. Foreign Language Annals, Volume 30 Issue 4 pp. 48549: American Council on the Teaching of Foreign Languages, Inc.

Richards, J \& Rodgers, T. (1986). Approaches and methods in language teaching. Cambridge: Cambridge University Press.

Robert, J. (1992). Production. In Sachs, W. (ed.). The Development Dictionary. New York: Zed Books.

Sachs, W. (1992). Environment. In Sachs, W. (ed.). The Development Dictionary. New York: Zed Books.

Sterling, S. (2001). Sustainable education. Re-visioning learning and change. Green Books.

Stevick, E.W. (1980). Teaching languages: A way and ways. Massachuttes: Newbury House. 